Abstract-Unobserved mortalities of nontarget species are among the most troubling and difficult issues associated with fishing, especially when those species are targeted by other fisheries. Of such concern are mortalities of crab species of the Bering Sea, which are exposed to bottom trawling from groundfish fisheries. Uncertainty in the management of these fisheries has been exacerbated by unknown mortality rates for crabs struck by trawls. In this study, the mortality rates for 3 species of commercially important crabs-red king crab, (Paralithodes camtschaticus), snow crab (Chionoecetes opilio) and southern Tanner crab (C. bairdi) - that encounter different components of bottom trawls were estimated through capture of crabs behind the bottom trawl and by evaluation of immediate and delayed mortalities. We used a reflex action mortality predictor to predict delayed mortalities. Estimated mortality rates varied by species and by the part of the trawl gear encountered. Red king crab were more vulnerable than snow or southern Tanner crabs. Crabs were more likely to die after encountering the footrope than the sweeps of the trawl, and higher death rates were noted for the side sections of the footrope than for the center footrope section. Mortality rates were $\leq 16 \%$, except for red king crab that passed under the trawl wings $(32 \%)$. Herding devices (sweeps) can expand greatly the area of seafloor from which flatfishes are captured, and they subject crabs in that additional area to lower (4-9\%) mortality rates. Raising sweep cables off of the seafloor reduced red king crab mortality rates from $10 \%$ to $4 \%$.

Manuscript submitted 7 March 2012. Manuscript accepted 9 November 2012. Fish. Bull. 111:42-53 (2013).

doi:10.7755/FB.111.1.4

The views and opinions expressed or implied in this article are those of the author (or authors) and do not necessarily reflect the position of the National Marine Fisheries Service, NOAA.

\title{
Quantification and reduction of unobserved mortality rates for snow, southern Tanner, and red king crabs (Chionoecetes opilio, C. bairdi, and Paralithodes camtschaticus) after encounters with trawls on the seafloor
}

\author{
Craig S. Rose (contact author) ${ }^{1}$ \\ Carwyn F. Hammond ${ }^{1}$ \\ Allan W. Stoner ${ }^{2}$ \\ J. Eric Munk ${ }^{3}$ \\ John R. Gauvin4
}

Email address for contact author: craig.rose@noaa.gov

1 Conservation Engineering Program Alaska Fisheries Science Center National Marine Fisheries Service, NOAA 7600 Sand Point Way NE Seattle, Washington 98115

2 Fisheries Behavioral Ecology Program Alaska Fisheries Science Center National Marine Fisheries Service, NOAA 2030 Marine Science Drive

Newport, Oregon 97365
3 Shellfish Assessment Program Alaska Fisheries Science Center National Marine Fisheries Service, NOAA 301 Research Court Kodiak, Alaska 99615

${ }^{4}$ Alaska Seafood Cooperative $424121^{\text {st }}$ Avenue W, Suite 302 Seattle, Washington 98199
The potential for unobserved mortality of crabs that encounter bottom trawls but are not captured has long been a concern for the management of groundfish fisheries in the Bering Sea (Witherell and Pautzke, 1997; Witherell and Woodby, 2005). Fisheries on the crab and groundfish stocks of the wide continental shelf of the eastern Bering Sea have made Dutch Harbor, the principal port for that area, the highest port by tonnage in the United States and 1 of the 2 highest ports by dollar value for more than 20 years. ${ }^{1}$ Three major crab species-red king crab (Paralithodes camtschaticus), snow crab (Chionoecetes opilio), and southern Tanner crab (C. bairdi)_are targets of large commercial fisheries (Otto, 1990). The 2 Chionoecetes species

\footnotetext{
${ }^{1}$ U.S. Department of Commerce. 19952011. Fisheries of the United States 1995 (1996,...,2011). Current Fishery Statistics 1995 (1996,_.,2011). U.S. Dep. Commer., NOAA, Natl. Mar. Fish. Serv., Fisheries Statistics Division, Silver Spring, MD. [Available from http:// www.st.nmfs.noaa.gov/commercialfisheries/fus/index.]
}

have similar low, flat body shapes and inhabit deeper water with muddier substrates than that of the red king crab, which has a thicker body and inhabits shallower, sandier areas (Jadamec et al., 1999; Donaldson and Byersdorfer, 2005). Groundfish species, particularly gadids and flatfishes are targeted with trawls. Overlaps between crab habitat and areas trawled by groundfish fisheries can result in some mortality for crabs that encounter groundfish trawls, either through capture and discard (bycatch) or as unobserved mortality of crabs that remain on the seafloor (Witherell and Pautzke, 1997).

The current management measures to control and reduce bycatch of the major Bering Sea crab species in Alaska groundfish fisheries include extensive year-round trawl closure areas (Fig. 1) and bycatch limits outside these areas. The yearround closure areas were established to protect areas of known concentrations of female and juvenile crabs. Armstrong et al. (1993) and Witherell and Pautzke (1997) cited unobserved trawl-induced mortality, along with 


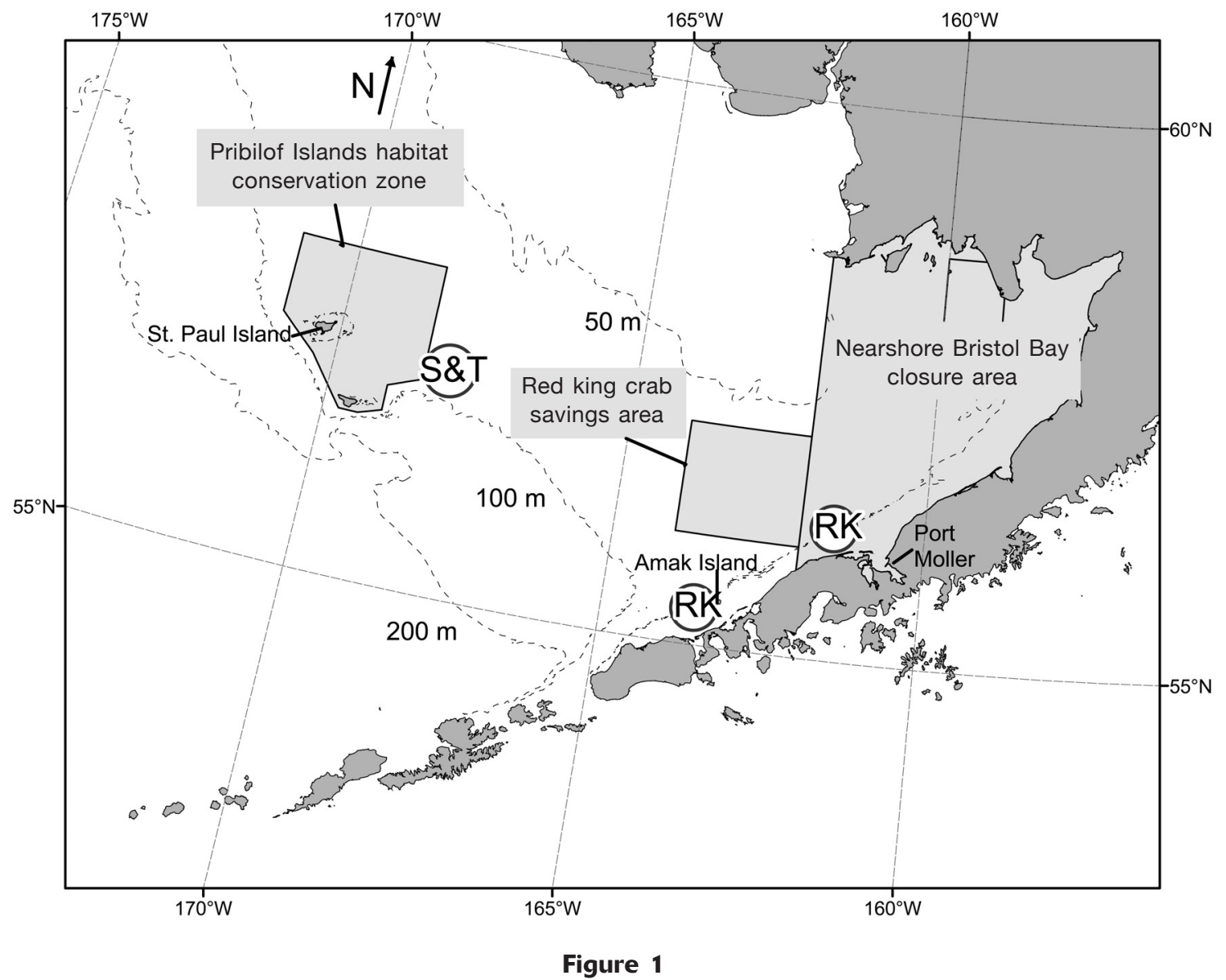

Sampling locations for snow (Chionoecetes opilio) (S) and southern Tanner (C. bairdi) (T) crabs in 2008 and red king crab (Paralithodes camtschaticus) in 2009 (RK), during our study of unobserved mortality rates from bottom trawling. Bottom trawl area closures (shaded) and depth contours are included for reference.

possible habitat degradation, as principal reasons for the establishment of these closures. Crab bycatch limits (on the basis of numbers caught) have also triggered additional closures if seasonal, species-specific (and sometimes area-specific) limits are reached. These bycatch numbers are obtained from onboard fishery observers on an in-season basis (Witherell et al., 2000). The species-specific crab bycatch limits (in estimated numbers of crabs brought aboard) are thought to have a biologically insignificant effect on the different crab populations because these limits have represented as little as $0.113 \%$ of the abundance index for snow crab and $0.5-1.0 \%$ of abundance for southern Tanner crab and red king crab (Witherell and Pautzke, 1997).

Critics of the existing framework of measures for crab bycatch management have from time to time asserted that, although bycatch limits appear to be sufficiently conservative, bycatch represents only a fraction of the actual mortality of different crab species caused by groundfish fisheries. Citing an unpublished technical paper, Thompson (1990) estimated actual trawl gear mortality for king crabs to be " 10 to 15 times the number of crabs that are caught in the net (and esti- mated by [National Marine Fisheries Service] observers)." These concerns cannot be adequately evaluated without addition of valid estimates of the unobserved mortality rates for these crab species to the assessments of bycatch and discard. Some crab researchers in Alaska (Murphy et al., 1994) also have underscored the need for additional research on injury rates and unobserved or unaccounted for mortality from both directed crab fisheries and groundfish trawl fisheries. Dew and McConnaughey (2005) concluded that excessively high mortality rates on male Bristol Bay red king crab from the directed fishery and unaccounted for mortality of females from the groundfish fisheries explain the downward population trajectory of this crab species through the late 1970s and early 1980s better than does the more accepted scientific hypothesis that the low population levels of red king crab were explained by unfavorable climate conditions.

Worldwide, the recognition of unobserved mortalities as a potentially significant element by the fishing industry and by fishery managers has increased the number of studies that have addressed such mortalities and the range of methods used in their estimation. 
Broadhurst et al. (2006) provided a thorough review of such studies. Although a great number of studies estimated mortalities of discarded catch, others dealt with mortalities of escaping animals not brought aboard the fishing vessel. Broadhurst et al. (2006) noted that studies of escaping animals, almost exclusively fishes, lately have emphasized methods where escaping animals are recaptured in cages that are then detached from the fishing gear while still at fishing depths. Those cages then are moved slowly to shallower depths, where they are maintained by divers long enough to assess delayed mortalities. Earlier methods involved capture of escaping animals in auxiliary nets before they were brought aboard and held long enough to evaluate mortality rates. However, stress and injury from recapture and extended towing and holding times could have easily masked or exacerbated the effects of the escape process, particularly for animals vulnerable to skin abrasion damage. More recent methods retain the experimental subjects in an environment closer to what they would experience after actual escape. The cost of these gains is that each collection of affected animals requires an extended series of activities that are time consuming and labor and resource intensive. These time and resource demands greatly restrict the number of experimental samples that can be collected and held and, hence, the number of experimental factors that can be addressed.

As an experimental subject, crab are significantly different from fish for which the in situ capture, transfer, and holding methods were developed. Exoskeletons protect crabs from the type of abrasion to which fish are particularly susceptible during net capture and crowded holding. As a trawl net approaches, fish continue swimming, often to exhaustion, to avoid contact with the net and other animals, but crab, being much slower, can flee only briefly before being overrun (Rose, 1995).

Another difference is how crabs interact with fishing gear. Broadhurst et al. (2006), describing research on fishes, noted, "Because most experiments have quantified escape mortality at the codend, the potential for mortalities as a result of collisions and escape through other parts of the gear have largely been ignored." Because of the sizes and behavior of Bering Sea crabs and the configurations of Bering Sea bottom trawls, most crabs escape under the forward parts of trawl systems, and interactions typically last only a few seconds as the crab passes the components of the net that directly contact the seafloor. Rose (1999) studied crab mortalities after such escapes under the forward sections of bottom trawls through assessment of visible injuries to red king crab that resulted from passes of crabs under different trawl footrope designs. The crabs were recaptured in an auxiliary net fished behind the main footropes. A control footrope, suspended with floats to allow crabs to pass beneath with minimal damage, also was used. A low rate of injuries for control crabs indicated that recapture of crabs to bring them aboard could be done without greatly increasing injury to crabs. The principal limitations of that study were the following: 1) crabs were not held beyond the initial assessment of injuries to observe delayed mortality; and 2) observations were limited to crabs that passed under the center section of the footrope, a small portion of the area swept during trawling.

Studying mortality of crabs discarded from trawl catches, Stevens (1990) effectively applied a strategy in which all subject crabs were assessed for selected condition attributes and a sample was held long enough to relate those attributes to delayed mortality. Since that study, such methods have been expanded and improved. Davis and Ottmar (2006) used assessment of a range of reflexes of Pacific Halibut (Hippoglossus stenolepis) to build a predictor of delayed mortality, the Reflex Action Mortality Predictor (RAMP). In a pilot study for this project, Stoner et al. (2008) found the RAMP technique effective for estimation of delayed mortalities for snow and southern Tanner crabs.

Our research addressed unobserved mortality rates for 3 principal commercial crab species of the Bering Sea: red king crab, southern Tanner crab, and snow crab. We improved methods for collection of crabs immediately after trawl encounters as used by Rose (1999) and applied the RAMP technique as described by Stoner et al. (2008) to assess the mortality probabilities for crabs that passed under the sweeps, wings, and central footrope of a commercial groundfish trawl. Raised sweeps, which reduce seafloor contact yet maintain herding of flatfishes (Rose et al., 2010), also were used at the red king crab sites to evaluate whether they would reduce crab mortality rates. Observations of control animals collected with identical recapture nets but no trawl encounter were used to adjust observed mortality rates for effects of capture and handling.

\section{Materials and methods}

A pilot study conducted in 2007 evaluated the RAMP and developed and tested techniques for 1) recapturing crabs after encounters with trawl components, 2) handling and assessing those crabs on deck, 3) holding selected crabs to determine their survival over several days, and 4) using the RAMP to estimate the mortality probability of each crab (Stoner et al., 2008). Our study followed those methods closely, and the following description summarizes them and highlights all modifications made to the methods of the pilot study for our later study.

Experimental tows for southern Tanner and snow crabs were made in August of $2008 \sim 111 \mathrm{~km}(\sim 60 \mathrm{nmi})$ east of Saint Paul Island (Fig. 1). All tows included a mix of both species. Red king crab tows were made in August of 2009 at 2 sites in Bristol Bay, about $22 \mathrm{~km}$ $(12 \mathrm{nmi})$ west of Amak Island and $\sim 65 \mathrm{~km}(\sim 35 \mathrm{nmi})$ northwest of Port Moller. Operations were conducted aboard the FV Pacific Explorer, a 47-m, 1800-hp com- 
mercial trawler equipped with a trawl configured similarly to the one used by many of the bottom trawlers that are used in Bering Sea groundfish fisheries. The 2-seam trawl net had a 36.0-m headrope and a 54.6$\mathrm{m}$ footrope, which was made of 19 -mm-long link +steel chain and equipped with bobbins $46 \mathrm{~cm}$ in diameter. The $\sim 70-\mathrm{cm}$ sections between bobbins were covered with 2 steel-chain toggles, weighing $6.4 \mathrm{~kg}$ each, rubber disks of $4-20 \mathrm{~cm}$, and one $5-\mathrm{kg}$ circular weight. Wing extensions, installed ahead of the forward ends of the footrope, were made of 20 -cm disks strung over $19-\mathrm{mm}$ long link chain. The cables (sweeps) that ran forward from the trawl to the doors were made of 48-mm combi-

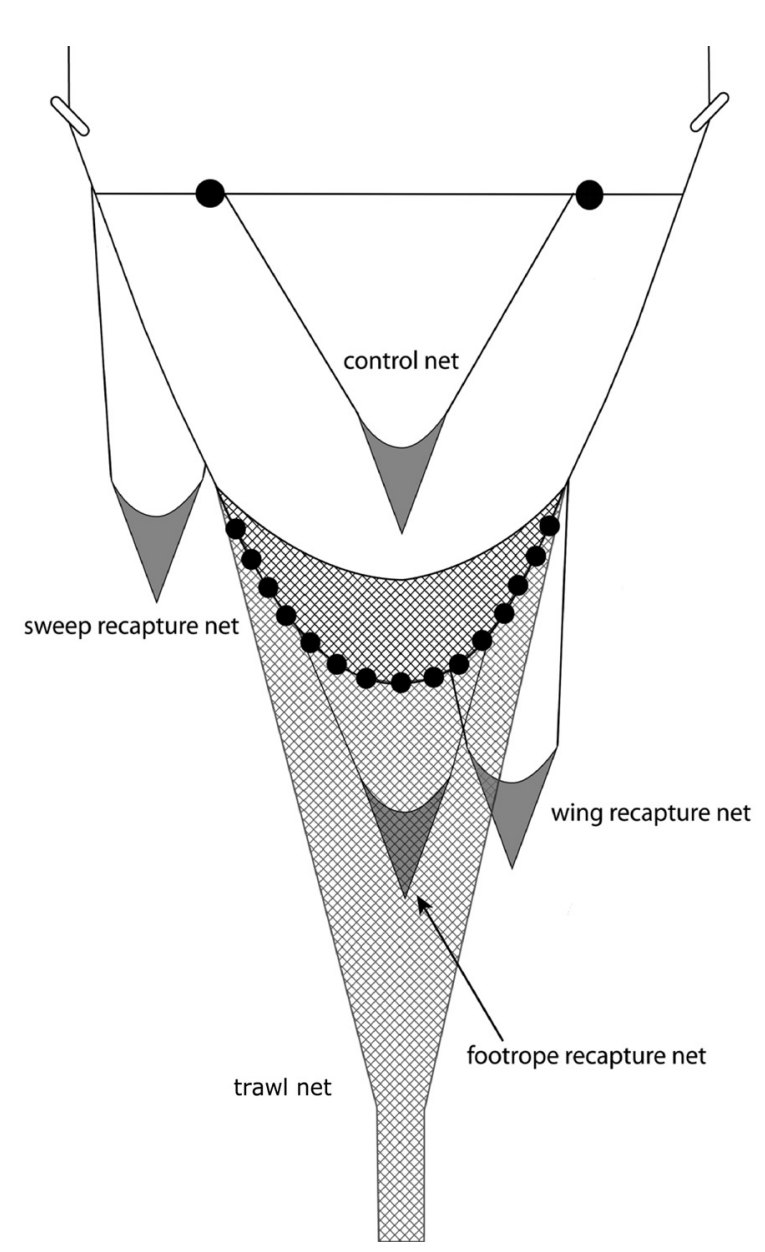

Figure 2

Diagram of the trawl net (not to scale) used in our study of unobserved mortality rates for snow crab (Chionoecetes opilio), southern Tanner crab (C. bairdi), and red king crab (Paralithodes camtschaticus), showing positions of recapture nets designed to retain crabs after contact with various trawl components. No more than 2 of these nets were fished during the same tow, and the control net always was fished separately. Illustration by Karna McKinney. nation rope, a product made of both steel and synthetic materials and used by most Bering Sea flatfish trawlers. The red king crab study included tests of sweeps equipped with disk clusters spaced at 14-m intervals and raised the combination rope $7.5 \mathrm{~cm}$ above the seafloor. Rose et al. (2010) found that such raised sweeps reduced seafloor contact while still herding groundfish effectively.

Crabs were captured immediately after contact with the components of the main trawl by small recapture nets fished behind these 3 gear regions: 1 ) at center of the footrope, 2) at the footrope wings (including their extensions), and 3) behind the sweeps (Fig. 2). These recapture nets were small trawls designed to minimize fish capture and maximize crab capture. The recapture nets used behind the wings and sweeps had unequal bridle lengths, which were adjusted until water passed perpendicular to the center of the headrope of each net, as observed with an underwater camera. An identical recapture net was fished ahead of the trawl as a control to assess damage and mortality due to handling. A rope between the sweeps ahead of the control net was necessary to avoid overspreading. That rope was raised $23 \mathrm{~cm}$ off the bottom of the seafloor to avoid affecting crabs. Only 1 recapture net was used at a time during every tow in 2008 to ensure that nets did not tangle when launched. Experience allowed us to expand to 2 nets ( 1 sweep and 1 footrope) at a time during some tows in 2009; however the control net was always fished alone because it would potentially have damaged crabs before they reached the footrope. The time required to change positions of the recapture nets on the trawls precluded alternating them between trawl components on a tow-by-tow basis; therefore, all tows that addressed each gear component were done in 1 or 2 blocks of sequential tows. To maximize holding times for crabs affected by the trawl, the control tows were done last. The codend of the main trawl was not closed because the tows were too short to represent typical mortality due to capture by the trawl, and catch volume was considered unlikely to significantly affect sweep and footrope mortality.

Towing speeds were $3-3.5 \mathrm{kn}$. Tow lengths were kept short to minimize damage to crabs from the recapture process but varied from 7 to $25 \mathrm{~min}$ to capture sufficient numbers of crabs. These speeds reflect industry practice, and, although commercial tows last much longer, the shorter lengths of the tows in our study did not change the relatively brief interactions between individual crabs and the ground contact components of the trawl. The main trawl was monitored with trawl sonar, which would detect any significant net asymmetry, and video observations of ground-gear components were used to check for atypical contact with the seafloor.

Tow sites (Fig. 1) were selected to provide adequate numbers of the targeted crab species during relatively short tows. Both snow and southern Tanner crabs were sufficiently abundant to be studied at a single site in 2008 , but red king crab research in 2009 required an 
additional site. Although one of the red king crab sites was in a closed area, both such sites were similar in depth and substrate to areas where Bering Sea groundfish fisheries encounter that species. If $<7$ individuals of a species were captured in one of the nets, crab assessments for that species were not used in the analysis. Tow tracks were arranged to minimize crossing the trawl tracks of previous tows and to keep such crossings close to perpendicular, to limit areas of overlap. Track crossings made up $<1 \%$ of study tows. We also maximized the time elapsed between such crossings (always more than 1 day) so that immediate mortalities from earlier exposure would be easily recognizable.

Upon recovery, the recapture codend was opened and all Chionoecetes crabs in 2008, or red king crab in 2009, were removed and sorted by species and sex (Jadamec et al., 1999). To use our project's resources most efficiently, we used a 2-stage sampling procedure in which all of the subject animals were assessed immediately for selected condition attributes and a small sample of those subjects was held long enough to relate those attributes to eventual mortality rates.

All Chionoecetes crabs were assessed for the presence of the 6 reflex responses described in Stoner et al. (2008): leg flare, leg retractions, chela closure, eye retraction, mouth closure, and kick. For red king crab, the leg retraction reflex test was replaced with a test of antennae movement response. Antennae, minuscule in snow or southern Tanner crabs, were quite active and responsive for red king crab, providing a more sensitive reflex response. As in the Stoner et al. (2008) eye and mouth tests, the antennae were manipulated and responsive movements were recorded as a positive response.

Assessments were limited to presence or absence of reflexes, there was no evaluation of reflex strength. This simplification allowed for rapid assessments and reduced any ambiguity or observer variation (Stoner et al., 2008). Initial scans separated unimpaired crabs from those crabs with an injury or at least one reflex missing. Missing reflexes and any injuries were recorded. Reflex scores indicated the number of impairments; a score of 0 indicated an unimpaired crab, and a score of 6 indicated a moribund crab with no reflexes present. Sex and shell condition for all crabs and carapace width for the 2 Chionoecetes spp. and carapace length for red king crab were recorded. Shell conditions (Jadamec et al., 1999) included soft shell (shell soft and pliable), new hard shell (firm to hard shell that lacked wear or encrustment), old shell (wear and encrustment present) and very old shell (extensive signs of shell wear and encrustment). Catch processing generally took less than $15 \mathrm{~min}$, and crabs were held in seawater when they were not being processed.

For each crab species, specimens representing each reflex score were tagged and held to estimate the relationship between reflex score and delayed mortality. Collections of snow and Tanner crabs in 2008 supplemented the RAMP results of the 2007 pilot study. Selec- tion of crabs for holding emphasized those with reflex scores from 1 to 5 , categories that had lower observed numbers in the earlier study. Holding procedures were identical to those of Stoner et al. (2008), with $\sim 900 \mathrm{~L}$ on-deck tanks, supplied with seawater flow $>20 \mathrm{~L} / \mathrm{min}$. Crabs were assessed daily, and those crabs that died were recorded and removed.

Early in the 2009 work, it became apparent that many of the red king crabs with no reflex impairments but apparent injuries were dying. This outcome indicated that fatally injured red king crab were not as likely to lose reflexes as were the Chionoecetes crabs and led us to adapt the full RAMP approach so that all red king crab that had either a missing reflex or an apparent injury were held. To ascertain how commonly fatal damage was completely hidden, 367 uninjured crabs displaying all reflexes were held.

Our estimator of the probability of mortality for crabs with each reflex score was the proportion of held crabs with that score that died for each species. To estimate overall mortalities, the proportions of crabs in each reflex class were multiplied by the probability mortality of that reflex class and summed (Eq. 1):

$$
m_{\mathrm{c}}=\Sigma_{\mathrm{r}=0 \text { to } 6}\left(m_{\mathrm{r}} * p_{\mathrm{rc}}\right),
$$

where $m_{\mathrm{c}}=$ the mortality estimate for a species in catch $c$;

$m_{\mathrm{r}}=$ the mortality probability from the RAMP for that species for reflex score $r$; and

$p_{\text {rc }}=$ the proportion of that species from catch $c$ with reflex score $r$.

For red king crab, this formula was modified to use the actual mortality outcomes of the injured and refleximpaired crabs, all of which were held for observation (Eq. 2):

$$
m_{\mathrm{c}}=\left(m_{\mathrm{u}} * p_{\mathrm{uc}}\right)+\left(\left(D_{\mathrm{ic}} / N_{\mathrm{ic}}\right) * p_{i \mathrm{c}}\right),
$$

where $D_{\text {ic }}=$ the number of impaired or injured crabs that died from catch $c$;

$N_{\text {ic }}=$ the number of injured or impaired crabs in catch $c$; and

$m$ and $p$ have the same meaning as in Equation 1 , except that $i$ refers to injured or impaired crabs and $u$ refers to those crabs that were uninjured with all reflexes present.

To estimate mortality for crabs that encountered a portion of the trawl, mortalities $\left(m_{\mathrm{c}}\right)$ for all catches from recapture nets installed in that area were averaged and weighted for the number of crabs in each catch.

To correct mortality estimates for handling damage, we assumed that gear and handling mortalities were independent and sequential. That is, where both processes occurred together in the recapture catches $\left(m_{\mathrm{g}+\mathrm{h}}\right)$, the gear mortality $\left(m_{\mathrm{g}}\right)$ occurred first and only those crabs not killed by the gear $\left(1-m_{\mathrm{g}}\right)$ were vulnerable to handling mortality $\left(m_{\mathrm{h}}\right.$, estimated as the mor- 
tality rate from the control net), resulting in Equation 3:

$$
m_{\mathrm{g}+\mathrm{h}}=m_{\mathrm{g}}+\left(\left(1-m_{\mathrm{g}}\right) * m_{\mathrm{h}}\right) .
$$

This equation was solved for $m_{\mathrm{g}}$, resulting in Equation 4:

$$
m_{\mathrm{g}}=\left(m_{\mathrm{g}+\mathrm{h}}-m_{\mathrm{h}}\right) /\left(1-m_{\mathrm{h}}\right)
$$

If the cumulative effects of gear impact and handling caused additional mortalities, this estimator would attribute those mortalities to gear effects, resulting in overestimated gear-caused mortalities.

To account for variability due to the combination of reflex score assessments, RAMP prediction of mortality, and corrections for handling mortality, a randomization approach was used for hypothesis testing and estimation of confidence intervals. A model of the experiment was implemented with the Resampling Stats add-in for Microsoft Excel (Resampling Statistics, Inc., Arlington, VA., http://www.resample.com). ${ }^{2}$ RAMP estimators were regenerated for each trial by making random binary draws for each reflex score category (Urn procedure) and by using the sample size and mortality probability for that score from the experiment. New probabilities, calculated from that draw, were then used in the mortality estimation procedure for that trial.

In resampling from the reflex assessments, we used each catch as our sample unit, choosing not to assume that individual crabs within a catch have independent mortality probabilities. To test null hypotheses that 2 groups of catches (e.g., catches from recapture nets at different trawl locations) actually came from the same population, the groups were combined and random draws were made from that combination, without replacement (Shuffle procedure), filling 2 new samples corresponding in number to the samples from the original experiment. A mortality estimate was generated for each trial by using the RAMP and assessment draws. For each test, 5000 trials were generated, and the proportion of those trials with differences greater than the observed estimate indicated the probability that our result occurred from a random process in which the mortality rates for both groups were equal.

Comparisons were made between catches from each of the 3 gear areas (center footrope, footrope wings and extension, and sweeps) and the control catches to determine whether those trawl encounters caused significant mortality. Subsequent tests were made for differences between the 2 footrope areas and between the sweeps and the combined footrope areas.

Confidence intervals were generated by a similar process, except that samples of the assessment catches for each group, including control catches, were randomly selected with replacement from the actual catches for that group. Handling corrections were applied to mortal-

\footnotetext{
${ }^{2}$ Mention of trade names or commercial companies is for identification purposes only and does not imply endorsement by the National Marine Fisheries Service, NOAA.
}

ity estimates generated for each gear component, on the basis of the control estimate from each trial. Confidence intervals $(95 \%)$ were generated by identification of the highest $2.5 \%$ and the lowest $2.5 \%$ of the estimates from 5000 trials.

Effects of sex, size, species, and shell condition on mortality rates were examined with logistic regression after the effects of each gear component were accounted for. Mortality was initially regressed against gear components, and the effects of these other factors were then tested against the residual variation. Because logistic regression requires binomial outcomes, specific RAMP probabilities of death could not be directly applied. Where direct observations from holding were not available, crab mortality outcomes were scored on the basis of whether RAMP probabilities for their mortality were less or greater than $50 \%$. Significant effects also were tested for interactions of each significant factor with gear area.

\section{Results}

The 159 total tows included 17-21 tows for each species at each recapture position. Between 154 and 991 crabs from each of the 6 combinations of species and sex were assessed after their capture behind each gear component and in the control position, and a substantial range of crab sizes were recorded within each combination (Table 1).

Augmentation of the Stoner et al. (2008) RAMP relationships for the 2 Chionoecetes species by holding additional crabs in 2008 had only minor effects on mortality rate estimates (Table 2) other than to reduce uncertainty due to larger sample sizes (Hammond, 2009).

For all 3 species, injuries varied widely in affected body part, type of damage, and severity, and were correlated with both reflex score and mortality rate. Of the red king crab with at least one missing reflex (reflex scores of 1 to 6), 96\% also had observable injuries, as opposed to only $5 \%$ of those crab with no missing reflexes (reflex score of 0 ). Crabs of all 3 species never survived removal of their abdomen or carapace, although autotomized legs (dropped off after injury) rarely caused fatalities. Crabs with either leg damage or carapace cracks normally survived, depending on extent, severity, and combination with other injuries.

Of the 485 surviving red king crab released at the end of this study, 482 had all reflexes present upon release, including all 14 that initially were missing at least one reflex. The $3 \mathrm{crab}$ that were missing a reflex upon release were all missing the eye reflex, had been held for 9 or 10 days, and had significant injuries, including carapace cracks. Although 25\% (122) of the surviving crab had detectable injuries, their survival through the holding period and vigorous state condition upon release indicated a low likelihood of significant later mortalities. 


\section{Table 1}

Number of crabs assessed and size ranges for each species and sex combination after they were captured behind 3 sections of bottom trawl gear, or with a control net. Size ranges, carapace width for snow (Chionoecetes opilio) and southern Tanner crabs (C. bairdi) and carapace length for red king crab (Paralithodes camtschaticus) are given in millimeters. The three gear components were the footrope wings or extensions, the center of the footrope, and the sweep. For red king crab only, a fourth component was added, a sweep raised off of the seafloor (Rose et al., 2010).

\begin{tabular}{|c|c|c|c|c|c|c|c|c|c|c|c|c|}
\hline & \multicolumn{4}{|c|}{ Snow crab } & \multicolumn{4}{|c|}{ Southern Tanner crab } & \multicolumn{4}{|c|}{ Red king crab } \\
\hline & \multicolumn{2}{|r|}{ Male } & \multicolumn{2}{|r|}{ Female } & \multicolumn{2}{|r|}{ Male } & \multicolumn{2}{|c|}{ Female } & \multicolumn{2}{|r|}{ Male } & \multicolumn{2}{|r|}{ Female } \\
\hline & No. & Size range & No. & Size range & No. & Size range & No. & Size range & No. & Size range & No. & Size range \\
\hline Control & 467 & $50-130$ & 154 & $54-92$ & 567 & $62-148$ & 157 & $56-100$ & 448 & $53-183$ & 433 & $82-145$ \\
\hline Sweep & 407 & $47-126$ & 218 & $52-93$ & 281 & $60-147$ & 518 & $59-98$ & 370 & $64-188$ & 226 & $63-150$ \\
\hline Raised sweep & & & & & & & & & 321 & $63-179$ & 278 & $68-148$ \\
\hline Footrope center & 991 & $46-140$ & 353 & $50-85$ & 677 & $50-145$ & 756 & $49-102$ & 753 & $69-189$ & 393 & $68-164$ \\
\hline Footrope wing & 696 & $48-130$ & 540 & $50-110$ & 288 & 51-143 & 494 & $52-97$ & 203 & 61-167 & 263 & $70-156$ \\
\hline
\end{tabular}

Most southern Tanner and snow crabs captured behind the main trawl components had all reflexes present $(76-93 \%$ reflex score of 0 , Fig. 3$)$, and the next most frequent category was dead crabs (reflex score of 6 , no reflexes present) upon capture (2-17\%). Similarly, a substantial majority (66-83\%) of red king crab captured behind the trawl gear was uninjured and had all reflexes present. Very few of these animals died during holding. Of the red king crab, 6\% were dead upon capture, making up $71 \%$ of mortalities. Therefore, nearly all of the observed crabs were either extremely likely to survive or moribund; relatively few crabs displayed an intermediate condition where the holding and RAMP results were critical to estimation of their probability of mortality.
For both red king and southern Tanner crabs, the control net yielded $97 \%$ uninjured crab with all reflexes present and no crabs were dead upon capture. Snow crab had more immediate mortalities in the control net $(2 \%)$ and only $88 \%$ had all reflexes present. Mortality estimates for crabs from the control nets (snow crab $7.1 \%$, southern Tanner crab $8.5 \%$, and red king crab $2.9 \%$ ) were significantly lower than the estimates for crabs captured behind trawl components.

Estimates of the rates of mortality due to contact with the trawl gear, adjusted for capture and handling, were below $16 \%$ (Fig. 4), with the exception of red king crab that encountered the wing section of the footrope, for which mortality was estimated at $31 \%$. Overall, estimated mortality rates for all 3 species were sig-

\section{Table 2}

Number of crabs held to observe delayed mortality and resulting mortality rates by reflex score (number of reflexes missing; 6 reflexes were assessed) and species for snow crab (Chionoecetes opilio), southern Tanner crab (C. bairdi), and red king crab (Paralithodes camtschaticus). Crabs from Stoner et al. (2008) were included for both Chionoecetes species.

\begin{tabular}{lcccccccc}
\hline & \multicolumn{7}{c}{ Number of reflexes missing } \\
\cline { 2 - 10 } & $\begin{array}{c}\text { None } \\
\text { missing }\end{array}$ & $\begin{array}{c}\text { None } \\
\text { missing + } \\
\text { injury * }\end{array}$ & 1 & 2 & 3 & 4 & 5 & $\begin{array}{c}\text { All } 6 \\
\text { missing }\end{array}$ \\
\hline Snow crab & 500 & - & 78 & 70 & 57 & 79 & 67 & 61 \\
Southern Tanner Crab & 375 & - & 53 & 35 & 37 & 47 & 38 & 18 \\
Red king crab & 367 & 145 & 49 & 55 & 60 & 38 & 21 & 1 \\
\hline & & & & Mortality rate (\%) & & & \\
\hline Snow crab & $1.4 \%$ & - & $20.5 \%$ & $30.0 \%$ & $43.9 \%$ & $75.9 \%$ & $88.1 \%$ & $100.0 \%$ \\
Southern Tanner Crab & $7.2 \%$ & - & $32.1 \%$ & $51.4 \%$ & $86.5 \%$ & $91.5 \%$ & $92.1 \%$ & $100.0 \%$ \\
Red king crab & $1.9 \%$ & $23.4 \%$ & $81.6 \%$ & $94.5 \%$ & $98.3 \%$ & $100.0 \%$ & $100.0 \%$ & $100.0 \%$ \\
\hline
\end{tabular}

\footnotetext{
* This category was used only for red king crab.
} 


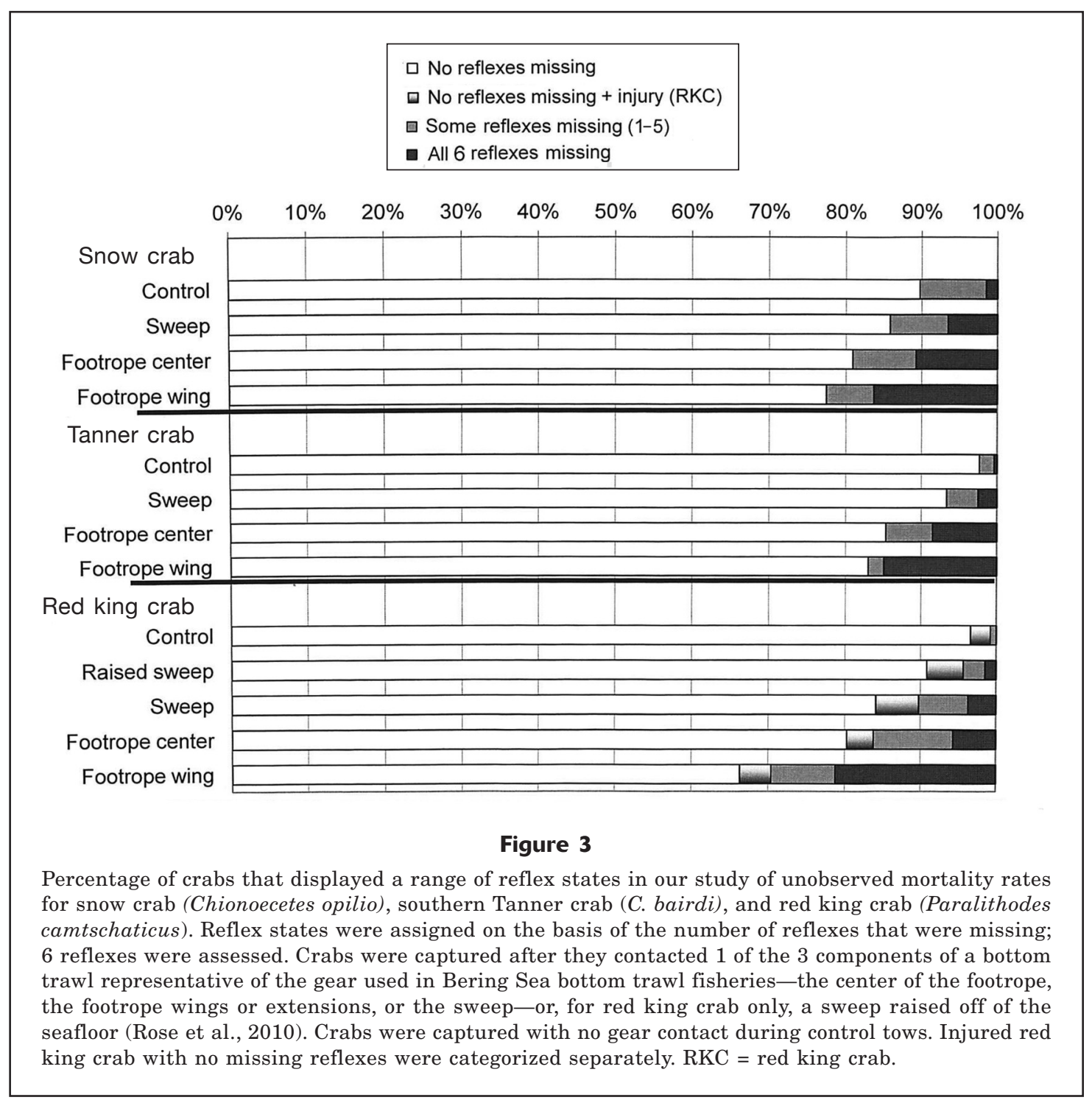

nificantly lower for crabs that encountered the sweeps than for those crabs that encountered the footrope and were higher for those crabs that encountered the wing portion of the footrope as opposed to the center footrope. Although the mortality rates for the southern Tanner and snow crabs were similar, both had lower mortality rates than did the red king crab for all trawl components. Raising the sweeps with widely spaced disk clusters reduced red king crab mortality from $10 \%$ to $4 \%$.

Holding only samples of the large numbers of crabs with no missing reflexes (no missing reflexes and uninjured for red king crab) greatly reduced the number of held crabs and produced minimal effects on precision of the mortality estimates. For example, the confidence interval estimation process was run with a sample size of 2581, representing all such red king crab observed, instead of the 367 crabs actually held. The resulting confidence range (high limit to low limit) for footrope wing mortality was reduced only from $14.25 \%$ to $13.99 \%$ by holding 7 times as many crabs. Confidence ranges for footrope center and sweep mortalities were reduced even less $(3.53 \%$ to $3.50 \%$ and $5.98 \%$ to $5.95 \%$, respectively).

Logistic regression was used to examine whether mortality rates varied by species, sex, size, and shell condition, after the effects of gear were removed. Nearly all crabs had either a new hard shell or old shell. For southern Tanner and snow crabs, marginally significant effects were detected between species, sexes, and sizes. When the mean effects across the combinations of those factors were examined, it was apparent that most of those effects were the result of higher mortalities for snow crab with carapace widths $>95 \mathrm{~mm}$; those large snow crab were nearly all males. Large snow crab were approximately twice as likely to die as smaller 


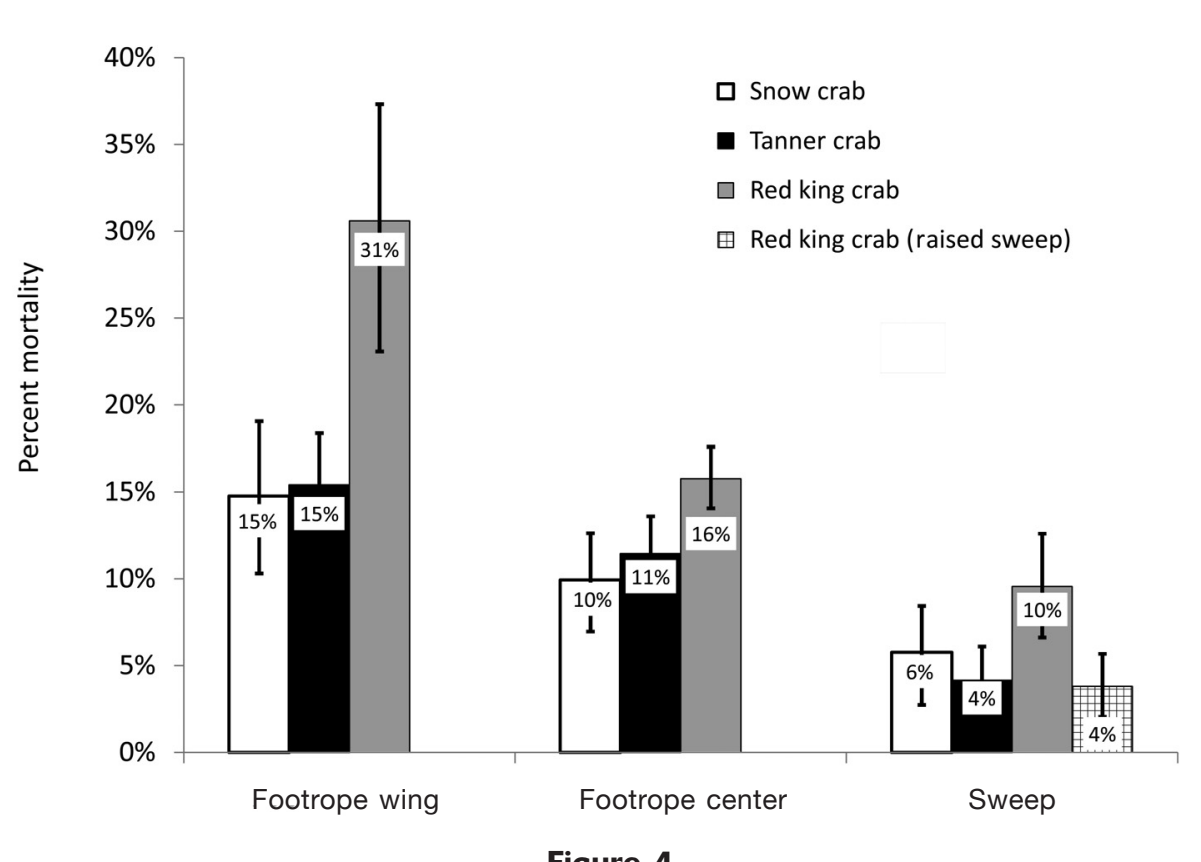

Figure 4

Estimates and 95\% confidence intervals of rates of mortality for snow crab (Chionoecetes opilio), southern Tanner crab (C. bairdi), and red king crab (Paralithodes camtschaticus that resulted from contact with 1 of 3 different components of a bottom trawl representative of the gear used bottom trawl fisheries in the Bering Sea-the footrope wings or extensions, the center of the footrope, or the sweep-and, for red king crab only, a sweep raised off of the seafloor (Rose et al., 2010).

snow crab or as any size of southern Tanner crab, and this difference persisted across all gear components and control catches.

Large red king crab had higher mortality than smaller king crabs $(P<0.001)$, although this effect explained $<1 \%$ of the variability in mortality, compared with $12 \%$ for the difference between gear components. The interaction between crab size and gear component was not statistically significant; therefore, there was no indication that this difference in vulnerability between sizes varied between gear components. Mortality of red king crab did not vary significantly between sexes or between new-hard-shell and old-shell crab. Although the percentage of mortalities was high for soft-shell crab (4 of 5 died) and crab with very old shells (3 of 5 died), those shell types were too rare for a statistical validation of difference.

\section{Discussion}

Our study provides the first reliable estimates of mortality rates following noncapture (not bycatch or discard) bottom trawl encounters for 3 commercially important crab species. Mortality rates varied by species but depended mainly on that part of the trawl system they encountered.
Crabs that passed under the trawl footrope, particularly in the wing sections, died at higher rates than those crab struck by the sweeps. Effective herding by sweeps greatly expands the area of seafloor from which flatfishes are captured. Mortality rates were substantially lower for crabs that encountered these herding devices in that expanded area than for crabs that encountered the trawl net itself, specifically the footrope. Therefore, enhancement of fish capture rates through effective herding can also reduce overall crab mortalities (i.e., capture of equivalent quantities of fishes without herding would expose more crabs to footrope components). The effective reduction of crab mortality through use of sweeps was further augmented for red king crab with modifications to raise sweeps a few centimeters above the seafloor (Rose et al., 2010).

The lower rates of unobserved crab mortalities from herding devices (i.e., sweeps), compared with mortality rates from trawl footropes, only partially indicate the potential of herding to reduce crab mortalities. Mortalities of crabs that encounter the footrope also would include those crabs retained in the net (bycatch). Stevens (1990) found that mortality rates were much higher for both captured red king crab (79\%) and captured southern Tanner crab (78\%) than for escaping crabs. Some herding of crabs is conceivable, but their much slower 
locomotion, compared with that of commercial fish species, led us to assume that the number of crabs that encountered each part of the trawl system is roughly proportional to the area swept by each part.

Red king crab had higher mortalities (6-32\%) than 2 species of Chionoecetes, snow and southern Tanner crabs (4-15\%) - a result that was expected given the generally smaller size and flatter body shape of Chionoecetes crabs. Overall mortality rates, weighted for the approximate relative areas swept by each trawl component for modern Bering Sea flatfish trawls (90\% sweeps, $6 \%$ footrope wings, $4 \%$ footrope center) were $6 \%$ for snow crab, $5 \%$ for southern Tanner crab, and $11 \%$ for red king crab. The raised sweeps reduce mortality rate for red king crab to $6 \%$. Such sweep modifications were required by the North Pacific Fishery Management Council for Bering Sea flatfish trawlers beginning in January 2011.

The trawl gear and methods selected for our experiment represented those gear and methods used in the Bering Sea flatfish fisheries. The gear is characterized by long, combination rope sweeps and footropes built with large-diameter, rubber bobbins or disks to keep the net mouth more than $20 \mathrm{~cm}$ above the seafloor. This footrope selection by the fleet has been driven partially by pressure to reduce crab bycatch. Decreasing bycatch through changes to gear means that more crabs pass under the trawl net. Although other Alaska bottom trawl fisheries (e.g., for Pacific Cod [Gadus macrocephalus]) use similar footropes, they use much shorter sweeps. Therefore, although cod trawls cover less seafloor (and hence contact fewer crabs) per kilometer towed than flatfish trawls, a higher proportion of the crabs might die because more of them would encounter the footrope components. The other major trawl fishery that can affect Bering Sea crabs is the fishery for Walleye Pollock (Theragra chalcogramma). Pollock trawls must meet a number of requirements that allow them to be considered "pelagic" trawls, but this fishery commonly has been fished with substantial seafloor contact.

Because regulations disallow any protective bobbins, none of the crab mortality estimates for gear components examined in our study can be used to estimate mortalities used for the pollock fishery, where chain footropes are used. The differences we found in mortality rates between different gear components indicate that changes in the specific gear configurations could improve or worsen crab mortality rates. The rates found here should not be applied to trawls with substantially different ground gear (e.g., chain footropes used in the Bering Sea pollock fishery). Component-specific mortality differences also present an opportunity to reduce crab mortality through identification of less damaging footrope configurations that sustain effective capture of target species. A companion study where an alternative footrope was tested has been completed (Hammond, 2009).
Because crabs were held for periods $<14$ days, our results did not include mortalities delayed over longer periods. The rapid drop of new mortalities after the first few days and the presence of all reflexes at the end of the study suggest that little additional mortality would be expected unless some other mechanism, such as infection or problems with molting, created a pulse of mortalities outside of the time period observed (see also Stoner et al., 2008). Likewise, holding crabs in ondeck tanks protected them from predation that would have increased delayed mortality if vulnerability to predation was enhanced by injury or stress after trawl exposure. Predators and scavenger species have been observed to move into areas recently swept by bottom trawls (Prena et al., 1999). Although this potential for additional mortality was not addressed directly in this study, the vast majority of the surviving crabs retained their full suite of assessed reflexes, including mobility of walking legs and defensive reactions. If predators initially focused on the more severely impaired and injured crabs that ended up as mortalities in our study, less impaired crabs might have some respite, allowing some time for recovery and reducing any difference between our results and the actual unobserved mortality due to predation.

All retained red king crab were held until the end of the study, 4 days after the control tows were completed. Because control crabs were held for only 4-6 days, we examined the proportions of delayed mortalities of crabs held for longer periods. For crabs held more than 10 days, $93 \%$ of the mortalities occurred in the first 4 days and $95 \%$ in the first 6 days. Because only 9 of the 881 red king crab caught in the control net died, the possibility of missing one additional mortality because of a shortened holding time was not considered to introduce a significant potential bias. Short holding time was even less of a concern for southern Tanner and snow crab because all of those crabs were held 7 days or longer and the low proportion of deaths after the first days noted during the pilot project (Stoner et al., 2008) continued during our 2008 observations.

In this study, the RAMP procedure (Stoner et al., 2008) was successful in prediction of mortality rates for many more crabs than we could have held to observe delayed mortality. Of all crabs assessed, $85 \%$ had either all reflexes present (Chionoecetes spp.) or were uninjured with all reflexes present (red king crab). Holding only one-eighth of these crabs provided generous samples ( $>350$ crabs per species) for estimation of their low mortality probabilities. If we had followed a conventional study method and held all crabs regardless of reflex state, more than 4 times as many crabs would have been held, with minimal reductions in uncertainty.

Although only representing a small proportion of the observed crabs, the RAMP procedure also allowed us to efficiently account for crabs with intermediate reflex assessments (reflex scores of 1 to 5). Because significant mortalities occurred to injured red king crab with all 
reflexes present, we held all those crabs, as well as all crabs of any of the 3 species with any missing reflexes. This procedure maintained the primary advantage of our RAMP assessments, accounting for a large group with high survival, and avoided the need to rely on injury assessments to estimate mortality. Both Stevens (1990) and Stoner et al. (2008) applied scoring systems for injuries, but the variety of injury types makes injury assessment more subjective and less likely to be repeatable than the reflex assessments.

We provided specific estimates of the unobserved mortality rates of crabs swept over by trawl gear common to bottom trawl fisheries in the Bering Sea. However, assessment of the effects of such mortalities on the populations of those crabs will require estimation of the portion of those populations exposed to trawling each year. Although the distribution of trawling effort is well documented by automated position monitoring of vessels and onboard observers, the spatial distribution of crabs throughout the year is not well known. A reliable estimate of the distribution of crabs, including seasonal variability, would be needed to estimate their exposure to trawling and allow for use of our mortality rate estimates in order to estimate resulting mortalities to the population. This approach would be subject to error from interannual and seasonal variations in crab distribution-variations that are not well understood and would be difficult to monitor.

The number of crabs captured in bottom trawls is monitored through catch sampling by onboard observers. Another way to estimate the number of crabs encountering trawls would be to learn the proportion of crabs that are caught in the path of a trawl. Crab bycatch data could then be expanded to estimate the number encountered, a value to which our mortality rates could be applied to estimate overall, unobserved mortality. One significant source of error for this approach is variability or changes in the specific footropes used across the fishery-differences that could substantially alter the proportion of crabs retained by the trawl. Also, should the trawl fishery approach its goal of eliminating crab bycatch, the base bycatch data could become sparse and even more variable.

\section{Conclusions}

Unobserved mortality is an important component of bycatch that is both easily overlooked and difficult to assess. Mortality rates for commercial crab species overrun by bottom trawls used in the Bering Sea varied substantially between the different components of trawls, with lower mortality for crabs that encountered sweeps than for crabs that encountered footropes. Reduction of mortality rates of red king crab from $10 \%$ to $4 \%$ by raising the sweeps off the seafloor showed that gear modifications can mitigate unobserved mortality.

\section{Acknowledgments}

This study was primarily funded under a grant from the North Pacific Research Board (project 711), with additional support from the National Cooperative Research and National Bycatch Reduction Engineering Programs of the National Marine Fisheries Service, NOAA. We gratefully acknowledge the substantial contributions of Captain L. Perry and his crew on the FV Pacific Explorer and the invaluable sampling efforts of P. Iseri, S. Walters, D. Evans, and K. Lee, and particularly D. Benjamin, who participated during all 3 summers of this study.

\section{Literature cited}

Armstrong, D. A., T. C. Wainwright, G. C. Jensen, P. A. Dinnel, and $\mathrm{H}$. B. Andersen.

1993. Taking refuge from bycatch issues: red king crab (Paralithodes camtschaticus) and trawl fisheries in the eastern Bering Sea. Can. J. Fish. Aquat. Sci. 50:1993-2000.

Broadhurst, M. K., P. Suuronen, and A. Hulme.

2006. Estimating collateral mortality from towed fishing gear. Fish Fish. 7:180-218.

Davis M. E., and M. L Ottmar.

2006. Wounding and reflex impairment may be predictors for mortality in discarded or escaped fish. Fish. Res. 82:1-6.

Dew, C. B., and R. A. McConnaughey.

2005. Did trawling on the brood stock contribute to the collapse of Alaska's king crab? Ecol. Appl. 15:919-941.

Donaldson, W. E., and S. C. Byersdorfer.

2005. Biological field techniques for lithodid crabs. Alaska Sea Grant College Program Report AK-SG-05-03, 82 p. Univ. Alaska, Fairbanks, AK. doi:10.4027/bftlc.2005

Jadamec, L. S., W. E. Donaldson, and P. Cullenberg.

1999. Biological field techniques for Chionoecetes crab. Alaska Sea Grant College Program Report AK-SG-99-02, 80 p. Univ. Alaska, Fairbanks, AK. doi:10.4027/ bftcc. 1999

Hammond, C. F.

2009. Using reflex action mortality predictor (RAMP) to investigate if trawl gear modifications reduce unobserved mortality of Chionoecetes sp. M.S. thesis, 52 p. Univ. Washington, Seattle, WA.

Murphy, M. C., W. E. Donaldson, and J. Zheng.

1994. Results of a questionnaire on research and management priorities for commercial crab species in Alaska. Alaska Fish. Res. Bull. 1:81-96.

Otto, R.S.

1990. An overview of eastern Bering Sea king and Tanner crab fisheries. In Proceedings of the international symposium on king and Tanner crabs; Anchorage, Alaska, 28-30 November, 1989, Lowell Wakefield Fisheries Symposia Series, p. 9-26. Alaska Sea Grant College Program Report 90-04. Univ. Alaska, Fairbanks, AK.

Prena, J., P. Schwinghamer, T. W. Rowell, D. C. Gordon, K. D. Gilkinson, W. P. Vass, and D. L. McKeown.

1999. Experimental otter trawling on a sandy bottom ecosystem of the Grand Banks of Newfoundland: analy- 
sis of trawl bycatch and effects on epifauna. Mar. Ecol. Prog. Ser. 181:107-124.

Rose, C. S.

1995. Behavior of North Pacific groundfish encountering trawls: applications to reduce bycatch. In Solving bycatch: considerations for today and tomorrow, $\mathrm{p}$. 234-242. Alaska Sea Grant College Program Report 96-03. Univ. Alaska, Fairbanks, AK.

1999. Injury rates of red king crab, Paralithodes camtschaticus, passing under bottom-trawl footropes. Mar. Fish. Rev. 61:72-76.

Rose, C. S., J. R. Gauvin, and C. F. Hammond.

2010. Effective herding of flatfish by cables with minimal seafloor contact. Fish. Bull. 108:136-144.

Stevens, B. G.

1990. Survival of king and Tanner crabs captured by commercial sole trawls. Fish. Bull. 88:731-744.

Stoner, A. W., C. S. Rose, J. E. Munk, C. F. Hammond, and M. W. Davis.

2008. An assessment of discard mortality for two Alaskan crab species, Tanner crab (Chionoecetes bairdi) and snow crab (C. opilio), based on reflex impairment. Fish. Bull. 106:337-347.

Thompson, A.

1990. An industry perspective on problems facing the rebuilding of king and Tanner (bairdi) crab stocks of the eastern Bering Sea. In Proceedings of the international symposium on king and Tanner crabs; Anchorage, Alaska, 28-30 November, 1989, Lowell Wakefield fisheries symposia series, p. 533-545. Alaska Sea Grant College Program Report 90-04. Univ. Alaska, Fairbanks, AK.

Witherell, D., C. Pautzke, and D. Fluharty.

2000. An ecosystem-based approach for Alaska groundfish fisheries. ICES J. Mar. Sci. 57: 771-777.

Witherell, D., and C. Pautzke.

1997. A brief history of bycatch management measures for eastern Bering Sea groundfish fisheries. Mar. Fish. Rev. 59:15-22.

Witherell, D., and D. Woodby.

2005. Application of marine protected areas for sustainable production and marine biodiversity off Alaska. Mar. Fish. Rev. 67:1-27. 